\title{
Homossexualidade indígena no Brasil: Um roteiro histórico-bibliográfico
}

\author{
Estevão Rafael Fernandes \\ Dept. de C. Sociais/Univ. Fed. de Rondônia
}

\begin{abstract}
Resumo: Este artigo busca sistematizar as referências sobre homossexualidade indígena na literatura clássica da etnologia brasileira, bem como apresentar textos recentes produzidos por antropólogos sobre a questão. O objetivo, mais do que apresentar um conjunto de textos e autores, é indicar a existência de um campo de estudos já consolidado (ainda que não necessariamente articulado internamente), por meio de pesquisas realizadas nos últimos anos, apontando também os desafios e perspectivas de se tomar "homossexualidade indígena" enquanto tema de investigação.

Palavras-chave: Sexualidade indígena, etnologia, Homossexualidade, Queer, relações interétnicas.
\end{abstract}




\title{
Indigenous homosexuality in Brazil: a historical-bibliographical review
}

\begin{abstract}
This article seeks to systematize the references about native homosexuality in the classical literature of Brazilian ethnology and present recent texts produced by anthropologists on the issue. The objective, rather than presenting a set of texts and authors, is to indicate the existence of an established field of study (although not internally articulated), through researches conducted in recent years, also pointing out the challenges and perspectives taking "indigenous homosexuality" as a research topic.
\end{abstract}

Keywords: Native Sexuality, Ethnology, Homosexuality, Queer, Interethnic relations

\section{La homosexualidad indígena en Brasil: Una revisión histórico-bibliográfica}

Resumen: En este artículo se pretende sistematizar las referencias acerca de la homosexualidad nativa en la literatura clásica de la etnología brasileña y presentar textos recientes producidos por los antropólogos sobre el tema. El objetivo, en lugar de presentar un conjunto de textos y autores, es para indicar la existencia de un campo establecido de estudio (aunque no articulado internamente), a través de investigaciones realizadas en los últimos años, señalando también los retos y perspectivas que tienen "la homosexualidad indígena" como tema de investigación.

Palabras clave: Sexualidad indígena, Etnología, Homosexualidad, Queer, Relaciones interétnicas 
O objetivo deste artigo é fornecer um roteiro que possa ser utilizado como ponto de partida para reflexões acerca das sexualidades indígenas que operam fora do modelo heternomativo hegemônico. Como veremos, trata-se de um campo no qual um conjunto de reflexões recentes vem surgindo, quase sempre chamando a atenção para as problematizações e implicações - epistêmicas, acadêmicas ou políticas - de se trabalhar um tema cujo próprio enquadramento não pode ser feito sem maiores ponderações.

Desta forma, cabem aqui algumas considerações de caráter preliminar. Em primeiro lugar, as várias fontes históricas disponíveis trabalham com diversos termos (como sodomia, pederastia e hermafroditismo, por exemplo), cada qual com um significado e existindo dentro de um contexto específico. Tais expressões não devem ser vistas como sinônimos entre si, tampouco entendidas como equivalentes à expressão "homossexualidade", nos termos utilizados hoje. No primeiro volume de seu História da sexualidade, Foucault (1988) já alerta para os desdobramentos dessa terminologia, sendo que tais palavras são produto de seu tempo e das motivações, em nosso caso específico, para colonizar, normalizando, os povos indígenas - inclusive (ou sobretudo, talvez) em sua sexualidade.

"Homossexualidade" é aqui, portanto, usado como termo guarda-chuva para incluir as formas não heteronormadas encontradas pelo colonizador e descritas pela pena de cronistas, missionários, antropólogos, viajantes e historiadores. Nesse sentido, as descrições sobre "homossexualidade indígena" devem ser encaradas aqui muito mais como uma expressão da obsessão colonizadora com a sexualidade indígena e seu controle: seu disciplinamento e este é um ponto que buscarei demonstrar aqui - é parte do projeto colonial desde o início, nos esforços por incluir as coletividades indígenas ora no conjunto de súditos da Coroa de Portugal, ora à "comunhão nacional".

Desta forma, tem-se aí uma agenda possível de pesquisas que busque recuperar os vários dispositivos e mecanismos discursivos acionados para essa incorporação, tendo como justificativas sua conversão, civilização ou integração por meio de práticas como corte de cabelo, nominação, casamentos interétnicos, batismo, incorporação compulsória ao mercado de trabalho e a um sistema de educação e moral impostos pelo colonizador; mas buscando em última medida o controle de sua mão de obra e/ou a desapropriação de seus territórios.

Este texto é, assim, mais que um exercício de levantamento bibliográfico, pretendendo-se sobretudo uma provocação para estudiosos interessados em compreender esse capítulo tão pouco explorado no âmbito dos estudos interétnicos e das relações coloniais no Brasil. Além disso, este trabalho busca apresentar um contraponto à narrativa, tão ouvida pelos estudiosos sobre a questão no país - inclusive junto a lideranças indígenas - de que a homossexualidade indígena, nos termos aqui expostos, seja sinal de uma "perda cultural", ou um "contágio advindo do contato". São bastante frequentes, como se verá a seguir, as referências a práticas homossexuais indígenas desde o século XVI, sem que isso repercutisse em preconceito ou agressão - exemplo infelizmente não mais seguido em várias aldeias do país, conforme pude observar ao longo de minhas próprias pesquisas sobre a temática. Assim sendo, mesmo a narrativa de "perda cultural" deve ser compreendida no âmbito da gênese e manutenção dos movimentos indígenas brasileiros bem como das relações entre esses povos e a sociedade envolvente, órgãos oficiais e instituições 
religiosas. Novamente, tem-se aí um universo de possibilidades a ser enfrentado por pesquisadores.

\title{
Um percurso histórico: recuperando a bibliografia
}

A homossexualidade indígena aparece de múltiplas formas em diversas fontes desde o início da colonização do Brasil. Autores como Gaspar de Carvajal (1540), Padre Manuel da Nóbrega (1549), Padre Pero Correia (1551), Jean de Léry (1557), Pero de Magalhães Gandavo (1576) e Gabriel Soares de Sousa (1587) fazem referência à homossexualidade indígena, especialmente entre os Tupinambá.

Pero Correia, por exemplo, em carta escrita em São Vicente em 1551 "para os irmãos que estavam em África” escreve logo no início de sua missiva que

\begin{abstract}
Escrevam-nos mais a miudo, como se hão em todas as cousas, para que saibamos cá como nos havemos de haver em outras semelhantes, porque me parece que estes Gentios em algumas cousas se parecem com os Mouros, assi em ter muitas mulheres e prégar polas manhãs de madrugada; e o peccado contra a natureza, que dizem ser lá mui commum, o mesmo é nesta terra, de maneira que ha cá muitas mulheres que assim nas armas como em todas as outras cousas seguem officio de homens e têm outras mulheres com quem são casadas. A maior injuria que lhes podem fazer é chamal-as mulheres. Em tal parte lh'o poderá dizer alguma pessoa que correrá risco de lhe tirarem as frechadas. (DESCONHECIDO, 1931: 97, negritei)
\end{abstract}

Nesse sentido, as observações de Pero Corrêa lembram muito o que escreve Gandavo:

\begin{abstract}
Algumas Indias ha que tambem entre elles determinam de ser castas, as quaes nam conhecem homem algum de nenhuma qualidade, nem o consentirão ainda que por isso as matem. Estas deixam todo o exercicio de mulheres e imitam os homens e seguem seus officios, como senam fossem femeas. Trazem os cabelos cortados da mesma maneira que os machos, e vão á guerra com seus arcos e frechas, e á caça perseverando sempre na companhia dos homens, e cada uma tem mulher que a serve, com quem diz que he casada, e assim se communicam e conversam como marido e mulher (GANDAVO, 1858 [1576]: 47-48)
\end{abstract}

Gabriel Soares de Sousa [1587], por sua vez, dedica todo um capítulo ao tema ("Que trata da luxúria destes bárbaros”):

\begin{abstract}
São os tupinambás tão luxuriosos que não há pecado de luxúria que não cometam; os quais sendo de muito pouca idade têm conta com mulheres, e bem mulheres; porque as velhas, já desestimadas dos que são homens, granjeiam estes meninos, fazendolhes mimos e regalos, e ensinam-lhes a fazer o que eles não sabem, e não os deixam de dia, nem de noite. É esse gentio tão luxurioso que poucas vezes têm respeito às irmãs e tias, e porque este pecado é contra seus costumes, dormem com elas pelos matos, e alguns com suas próprias filhas; e não se contentam com uma mulher, mas têm muitas, como já fica dito pelo que morrem muitos de esfalfados [cansaço]. [...] são muito afeiçoados ao pecado nefando, entre os quais se não têm por afronta; e o que se serve de macho, se tem por valente, e contam esta bestialidade por proeza; e nas suas aldeias pelo sertão há alguns que têm tenda pública a quantos os querem como mulheres públicas. (SOUSA, 2000: 235-236, negritei)
\end{abstract}

Em comum nas narrativas mencionadas, o olhar abjeto, servindo como uma das justificativas para a colonização, fazendo uso sobretudo da conversão a partir do medo.

O relato escrito pelo padre capuchinho francês Yves D'Evreux intitulado Viagem ao Norte do Brasil (1613-1614) (Voyage au nord du Brésil fait en 1613 et 1614) é especialmente emblemático nesse sentido. Escreve o padre que 
Ha em Juniparan, na Ilha, um hermaphrodita, no exterior mais homem do que mulher, porque tem a face e voz de mulher, cabelos finos, flexíveis e compridos, e comtudo casou-se e teve filhos, mas tem um genio tão fórte que vive porque receiam os selvagens da aldeia trocar palavras com elle. (D’EVREUX 1874: 90)

\title{
Ao fim, levaram o condenado
}

junto da peça montada na muralha do Forte de S. Luiz, junto ao mar, amarraram-no pela cintura á bocca da peça e o Cardo vermelho lançou fogo á escorva, em presença de todos os Principaes, dos selvagens e dos francezes, e immediatamente a bala dividio o corpo em duas porções, cahindo uma ao pé da muralha, e outra no mar, onde nunca mais foi encontrada (: 233)

Outra referência interessante - ainda que não tão chocante - é o texto intitulado "Noticia sobre os Indios Tupinambás, seus costumes, etc. extractada de um manuscripto da Bibliotheca de S.M. o imperador", publicado no primeiro número da Revista do Instituto Histórico e Geographico do Brazil1, escrita por Gabriel Soares de Sousa, autor do Tratado descritivo do Brasil (1587):

\begin{abstract}
Não satisfeitos com esta vida de brutos, nem bastando esta liberdade para saciar a vontade venerea, são incessantemente dados ao peccado de sodomia, tendo-se por mais graves os que mais a frequentam; e não admitindo differença entre agente e paciente; motivo por que com a mesma publicidade o executam. Como a natureza humana não tem forças naturaes para suportar um tão continuado excesso, a ajudam estes gentios com unções, e refeições de certos oleos e hervas, em que a malicia tem descoberto virtude para este auxilio; e na verdade coopera muito para o seu intento. Mas a mesma natureza depravada os affrouxa, debilita e os mata esfalfados, posto que satisfeitos com as proezas que fizeram. (: 164)
\end{abstract}

Em 1639 surge outra fonte interessante: um pequeno texto de Elias Herkman (republicado em 1886) sobre a capitania da Paraíba, também remetendo aos tibira (Herkman, 1886). Entre 1639 e 1795 não encontrei publicações com menções a homossexualidade em aldeias indígenas. Entendo que uma das razões para isso esteja na mudança observada nesse período no tocante ao regime discursivo sobre a sexualidade, saindo gradualmente de uma visão pautada no julgamento moral rumo a uma perspectiva mais pragmática. $\mathrm{O}$ fim do século XVIII deixa clara essa passagem, consolidada ao longo do século XIX, a partir da qual temos o relato de militares cujos registros trazem já claras marcas de um ponto de vista mais objetivo, ainda que não necessariamente neutro.

Assim, temos na época registros como os de Francisco Rodrigues do Prado (militar) sobre os Guaykuru (em 1795, referido aqui como Rosário, 1839), Adolfo de Varnhagen (militar e historiador) sobre os Tupi (Varnhagen, 1854) e Couto de Magalhães (militar e etnógrafo) sobre a homossexualidade indígena entre os Karajá, Chambioá, Curajahis e Javaé (Magalhães, 1876). Vejamos.

No mesmo exemplar da Revista do Instituto Historico e Geographico do Brazil em que a Notícia sobre os índios Tupinambas de Soares de Sousa foi publicada, publica-se o artigo "Historia dos índios cavalleiros, ou nação guaicurú, escripta no real presídio de Coimbra por Francisco Rodrigues do Prado - Trasladada de um manuscripto offerecido ao Instituto pelo socio correspondente José Manoel do Rosário”, originalmente escrito em 1795:

Entre os Guaycurús ha homens que affectam todos os modos das mulheres; vestemse como ellas, occupam-se em fiar, tecer, fazer panellas \& etc. A estes chamam Cudinas, nome que dão a todo o animal castrado; e verdadeiramente elles são as meretrizes desta nação, que faz uso do peccado amaldiçoado por São Paulo, e outros 
que impedem a propagação humana. [...] Os Guayacurús chegavam-se aos nossos, e pondo-lhes as mãos nos hombros como por amizade os sacudiam, e conforme a sustancia que encontravam, assim ficavam junto a elles aquelles que julgavam necessarios para matar. Tantas demonstrações não despertavam nos portuguezes a lembrança das grandes perdas que os bárbaros lhes tinham feito. O interesse de comprarem as bagatellas que os gentios traziam lhes entorpeceu o entendimento: se não foi a divina providência, que nelles quis castigar os peccados que foram a causa de subverter-se Sodoma e Gomorra. (ROSARIO, 1839: 32-33; 49)

Couto de Magalhães registra a existência, entre os Chambioá, de um grupo de homens dedicados a servir sexualmente a outros:

\begin{abstract}
Tomemos agora um outro typo mais severo ainda que o Guató, e na bacia do Amazonas, o Chambioá. Os Chambioás com os Carajas, Curajahis e Javaés, formam uma só nação, com sessenta ou oitenta aldêas espalhadas á margem do rio Araguya, desde o furo Bananal até as Intaipabas (itaypabe, agua que corre sobre pedregal), o que mede uma extensão de 120 a 125 léguas, e com uma população de cerca de sete a oito mil individuos. Entre esses indios ha dois factos minimamente curiosos nas instituições que regulam as relações do homem com a mulher. O primeiro d'estes é o haver nas aldêas homens destinados a serem viri viduarum. Esses individuos não têm outro mister; são sustentados pela tribu, e não se entregam, como os outros, aos exercícios das longas viagens e peregrinações, que todos fazem annualmente, embora revesando-se. Esta singular casta, sustentada pelos outros, despertou-me a curiosidade; e tendo eu pela primeira vez notado o facto em uma aldêa, cujo capitão era homem muito intelligente, de nome Coinamá, tive occasião de notar-lhe que me não parecia justo, que a aldêa carregasse com o sustento d'esses homens. Elle retorquiu-me que a paz de que gozavam as familias, e que não gosariam a não serem aquelles individuos ou antes essa instituição, compensava de muito o trabalho que pesava sobre os outros sustental-os [o segundo fato curioso ao qual se refere o autor é, supostamente, os Chambioás queimarem as mulheres adúlteras]. (MAGALHÃES, 1876: 115-116)
\end{abstract}

Por sua vez, Varnhagen, em seu célebre História Geral do Brasil, cujo primeiro tomo foi publicado em 1854 , indica que:

Os invasores bárbaros [o autor refere-se aos Tupi] traziam comsigo bastantes germens de discordia, que vieram a dar mui sasonados fructos venenosos nas suas novas terras. Apenas uns venciam, vinham outros arrancar-lhes das mãos a palma da victória, e as hostilidades e vicios não tinham fim. Entre os ultimos era sobretudo lamentavel a paixão com que se davam ao peccaminoso attentado que o Senhor condemnou em Sodoma, vicio infame que alêm de ser degradante para o homem, tanto contribuaia a que a população se diminuisse cada vez mais, em vez de augmentar-se. Também não contribuiam menos a diminuir a população os crimes de envenenamentos frequentes, ás vezes de si proprios, pelo uso de comer terra e barro. (VARNHAGEN, 1854: 107)

O texto de Varnhagen nos oferece algumas informações interessantes: a sodomia apresenta-se incluída em um conjunto de vícios. Até aí, sem grandes novidades com relação ao que desde os jesuítas e cronistas quinhentistas se escrevia, não fosse a observação seguinte: seu efeito era a diminuição de sua população. Dessa forma, a prática de homossexualidade entre os indígenas passava a ser julgada objetivamente, posta em paralelo com outras práticas cuja consequência era a diminuição da população - como envenenar-se comendo terra, por exemplo. 
Além desses, outros etnógrafos do período (fim do século XIX, início do século XX), ambos alemães, virão a descrever práticas homossexuais nas aldeias brasileiras: Karl von den Steinen entre os Bororo ([1894] 1916) e Curt Nimuendaju, sobre a mitologia2 Apapocuva-Guarani (1987 [1914]) e sobre os Tikuna (1952), a partir de um texto de Günter Tessmann3.

Steinen, em uma bela descrição indica que

\begin{abstract}
Quão elegante e nitidamente os homens trabalhavam, - notava-se principalmente no arranjo das flechas. Havia ahi muitas habilidadesinhas, que parecia mais natural devessem ser confiadas ás delicadas mãos femininas. Por exemplo, o adôrno feito de miudinhas e variegadas pennugens, que eram postas uma a uma no chão e meticulosamente arranjadas. E mesmo uma roda de fiandeiras não se podia mais tagarellar e rir do que ahi no baíto! Certamente era pouco feminino, quando, de repente, para variar, levantavam-se dous dos trabalhadores, offerecendo o espetaculo de uma regular lucta corporal, que os outros accompanhavam com o maior interesse. Erguiam-se, luctavam, derrubavam-se e continuavam depois o seu trabalho, ou deitavam-se para o dolce far niente. Pois nunca faltavam preguiçosos e indolentes; muitas vezes encontravam-se tambem pares enamorados, - posto que as mulheres não apparecessem alli, - que se divertiam debaixo de um commum cobertor vermelho. Ninguem se incomodava com isso, excepto alguns amigos atormentados pelo ciume e que haviam de contentar-se com o poderem sentar-se ao lado do casal e palestrar com este. (STEINEN, 1916 [1894]: 452)
\end{abstract}

Outra referência à homossexualidade indígena provém de Freyre, em Sobrados e Mucambos, em seu capítulo intitulado "A mulher e o homem”, na qual ele discute a descrição de casais de homens Bororo trazida pelo etnógrafo alemão Karl von den Steinen, citado acima. Soma-se a esses o estudo de Guido Boggiani intitulado Os Caduveo, onde consta um apêndice escrito por Giuseppe Angelo Colini ("Notícia histórica e Etnográfica sobre os Guaicuru e Mbayá”): “é recordada uma classe de homens que imitavam as mulheres, não só vestindo à sua maneira mas se dedicando às ocupações reservadas às mesmas, isto é, fiar, tecer, fazer louças, etc." (Colini, 1895).

Já na década de 1940 Lévi-Strauss reservaria espaço para o tema em um artigo publicado em 1943 sobre terminologia de parentesco entre os Nambikwara (Lévi-Strauss, 1943). Na mesma década, Alfred Métraux (1948: 324) aponta que entre os Mbyá a existência de "berdaches" seria comum, com eles se vestindo de mulheres, simulando menstruar e realizando atividades femininas, sendo vistas como as "prostitutas da aldeia”. No ano seguinte, Charles Wagley e Eduardo Galvão apontariam para a prática, entre meninos adolescentes Tenetehara, de usarem meninos de 5 anos "como meninas" 
(Wagley e Galvão, 1949: 79). Carneiro (1958) aponta como as crianças Kuikuru do mesmo sexo podem ser vistas brincando de sexo (:140). Já Murphy e Quain (1955) mencionam a existência de relações sexuais entre garotos e homens entre os Trumai, sem que uma eventual ereção seja digna de maior atenção por parte dos observadores.

$\mathrm{Na}$ etnologia brasileira o caso mais conhecido de um indígena homossexual certamente é aquele trazido por Pierre Clastres, no capítulo intitulado "O arco e o cesto", em A Sociedade contra o Estado (1974). Nele, o autor reflete sobre Krembegi, um índio Guayaki homossexual. Esse personagem, encontrado por Clastres durante seu período de campo no Paraguai, na década de 1960, era, nos dizeres do autor,

\begin{abstract}
na verdade um sodomita. Ele vivia com as mulheres e, à semelhança delas, mantinha em geral os cabelos nitidamente mais longos que os outros homens, e só executava trabalhos femininos: ele sabia "tecer" e fabricava, com os dentes de animais que os caçadores lhe ofereciam, colares que demonstravam um gosto e disposições artísticos muito melhor expressos do que nas obras das mulheres. Enfim, ele era evidentemente proprietário de um cesto [em contrapartida ao arco, epítome da masculinidade] [...]. Esse pederasta incompreensível vivia como uma mulher e havia adotado as atitudes e comportamentos próprios desse sexo. Ele recusava, por exemplo, tão seguramente o contato de um arco como um caçador o do cesto; ele considerava que seu lugar natural era o mundo das mulheres. Krembegi era homossexual porque era pane [ou seja, tinha azar na caça]. [...] para os próprios Guayaki ele era um kyrypy-meno (ânus-fazer amor) porque era pane. (CLASTRES, 2003: 126)
\end{abstract}

O autor lhe reservaria ainda um capítulo em outra obra, Crônica dos índios Guayaki (1972), intitulado "Vida e morte de um pederasta", no qual parte do argumento acima fica mais claro:

Homem=caçador=arco; mulher=coleta=cesta: dupla equação cujo rigor regula o
curso da vida Aché. Terceiro termo, não há, nenhum terceiro-espaço para abrigar os
que não são nem do arco nem da cesta. Cessando de ser caçador, perde-se por isso
mesmo a qualidade de homem, vira-se, metaforicamente, uma mulher. Eis o que
compreendeu e aceitou Krembegi; sua renúncia radical ao que é incapaz de ser -
caçador - projeta-o de imediato do lado das mulheres, ele está em casa entre elas, ele
se aceita mulher. (CLASTRES, 1995: 212)

Interessante notar que, apesar de surgirem na literatura antropológica brasileira algumas referências à figura de Krembegi, isso ocorre em autores que buscam discutir aspectos gerais da obra de Clastres, sem que seja dada, na maioria dos casos, uma atenção mais detida ao que postula o autor nos trechos citados acima especificamente sobre a sexualidade de Krembegi.

Poucos anos depois é publicado texto sobre os Tapirapé no qual Wagley (1977) menciona que homens, no passado, manteriam sexo anal com outros homens, de quem seriam os favoritos e a quem acompanhariam nas caçadas. 
Ainda que não houvesse nenhum desses indivíduos vivo quando realizou seu trabalho de campo, seu informante teria lhe fornecido o nome de cinco deles, os quais permitiriam que os homens mantivessem sexo anal à noite, na casa dos homens. O pai de seu informante havia lhe dito que um desses homens teria nome de mulher e faria trabalho de mulher, e esse "homem-mulher" [manwoman] teria morrido por estar grávido: "seu estômago inchou, mas como não havia útero, não havia como o bebê nascer”. Wagley registra que nenhum de seus informantes jamais havia ouvido falar de uma mulher que mantivesse papel masculino ou preferisse sexo com outra mulher (Wagley, 1977: 160). Como vimos, a menção que Wagley (1977) faz a um homem grávido vem a somar-se àquela, já citada aqui, escrita por Lévi-Strauss, em sua descrição sobre o mito Xerente de origem das mulheres, ao escrever que "antigamente não existiam mulheres, e os homens eram homossexuais. Um deles ficou grávido e, como não podia parir, morreu” (Lévi-Strauss, 2004 [1964]: 139), ou daquela descrita por Jerá Guarani adiante.

No mesmo ano em que Wagley publica o texto acima, o antropólogo Thomas Gregor relata a existência de relações homossexuais femininas entre pré-adolescentes Mehinaku:

some prepubescent girls enter into casual lesbian relationships. Since the participants
in these experimental affairs are mercilessly teased if they are exposed, village
children must become acquainted at an early age with the arts of concealment they
will employ in adult life". (GREGOR, 1977: 116) 4

Alguns anos depois o mesmo autor reservaria trecho de seu Anxious pleasures: the sexual lives of an Amazonian people, também sobre os Mehinaku (1985), para tratar sobre o tema. Segundo ele, a ideia de relações homossexuais soaria ridícula para aqueles índios, sendo os casos de homossexualidade existentes influência dos não indígenas, mantidos como estratégia para obtenção de presentes. Contudo, Gregor cita o caso de Tenejumine, "levemente uma mulher”. Nascido de um pai que queria uma filha durante a relação sexual, ele cresceu assumindo o papel feminino, bem como seus enfeites, pinturas e corte de cabelo, tendo "voz aguda e pequenos seios". Os homens, segundo se conta, se deitariam ao seu lado na rede e fingiriam ter sexo com ele, como meio de obter presentes. 
Também se passam na rede as relações descritas por Hugh-Jones entre os Barasana (Tukano):

\begin{abstract}
boys approaching initiation are sometimes involved in homosexual teasing which takes place in hammocks in public: this play is most common between initiated but unmarried youths from separate exogamous groups. (1979: 160-161)5
\end{abstract}

A questão do preconceito, ou não, dos indígenas homossexuais (dentro e fora de suas aldeias) começa a aparecer em relatos mais recentes sobre o tema. Para Torrão Filho, por exemplo, entre os Tupinambá os homossexuais apenas eram alvo de discriminação quando não desempenhariam as obrigações masculinas de caçar e guerrear, mas nunca por suas preferências sexuais:

\begin{abstract}
Havia mesmo homens passivos que mantinham cabanas próprias para receberem seus parceiros e muitos possuíam "tenda pública", recebendo outros homens como se fossem prostitutas. Aqueles que eram ativos chegavam a vangloriar-se destas relações, considerando-as sinal de valor e valentia, embora o termo tivira ou tibira fosse, por vezes, utilizado como ofensa. Entre as mulheres, algumas adotavam os penteados e as atividades masculinas, indo com eles à guerra e à caça, além de casarem-se com outras mulheres, adquirindo toda espécie de parentesco adotivo e obrigações assumidas pelos homens em seus casamentos; eram as chamadas çacoaimbeguira. (TORRÃO FILHO, 2000: 222)
\end{abstract}

\title{
Outra referência sobre o assunto é o texto de José Silvério Trevisan
}

(Devassos no paraíso: A homossexualidade no Brasil, da Colônia a atualidade), no qual são mencionadas as "práticas homossexuais” entre os Krahó (cunin, p. ex. "fazer cunin"):

\begin{abstract}
Sérgio6 contou que, à noite, acordava frequentemente com ruídos de solteiros bolinando-se no kó, onde dormem agarrados e abraçados. Quando se trata de transar, os rapazes preferem ir para o mato. Sérgio tornou-se amigo de um belo índio kraô de 15 anos, que incansavelmente e de maneira bem explícita o convidava para "fazer cunin": "Eu ponho na sua bunda e depois você põe na minha" (...) Certa vez, ele interrompeu uma aula de português que Sérgio dava aos garotos e, em público, mostrou-lhe seu pinto duro, convidando-o mais uma vez para fazer cunin, enquanto ele próprio e os demais índios riam divertidos. (...) em contrapartida, quando abraçou pelos ombros um motorista da Funai, o índio foi enxotado: "Isso não é hora de macho estar me abraçando", retrucou o motorista branco, irritado. (TREVISAN, 2004: 224; apud ALEXANDRINO, 2009: 19)
\end{abstract}

\section{Nesse texto de Trevisan aparece o "kudina" entre os Kadiwéu:}

Trata-se de figuras absolutamente integradas ao grupo social, que os reconhece como grandes artistas. Darcy [Ribeiro] observou, aliás, que em geral, "os índios se mostram muito livres em suas manifestações de afeto". Além de viver agarrados uns aos outros, "curtem se tocar e conversar bem juntinhos; inclusive os homens; mal eu chegava numa aldeia, eles logo me cercavam e vinham se encostando". Supõe-se que nesse contexto, expressões mais erotizadas de relacionamento intermasculino não provocam na tribo tamanha estranheza quanto nas sociedades ocidentais brancas. (TREVISAN, 2004: 223; apud ALEXANDRINO, 2009: 19)

5 "Meninos que se aproximam da iniciação são envolvidos às vezes em provocações homossexuais que ocorrem em público nas redes: essa brincadeira é mais comum entre jovens iniciados, mas solteiros, de grupos exogâmicos separados". (Traduzi)

6 Estudante de filosofia, que trabalhava para a Funai como professor e enfermeiro. 
A passagem acima refere-se à descrição dos Cudina feita por Darcy Ribeiro:

\begin{abstract}
Uma criança ao nascer pode ser devotada pelos pais a diferentes destinos, e isso é definido, em grande parte, pela forma de cortar o cabelo assim que ela nasce. Pode-se cortar o cabelo de uma forma tal que todo mundo saiba, vendo o menino, que ele vai ser uma pessoa doce, cordial, que fará roças e chegará até ao exagero de cultivar em lugar de tomar os produtos de roças alheias. Cuidará muito da família, será uma boa pessoa na aldeia, muito confiável. Dentro dessa linha, ele poderá até chegar a ser um "cudina”. Ou seja, se declarar mulher. Nesse caso, vestirá uma saia, como as mulheres, e se comportará como um homossexual. Entre os Kadiwéu isso é uma coisa muito séria. $\mathrm{O}$ homossexual se casa para ter marido, devota-se à arte da pintura de corpo com grande virtuosidade e até simula menstruar-se. Como as mulheres menstruadas, não sendo fodíveis, ficam num cantinho da aldeia, quando se juntam muitas o "cudina” vai lá também participar do mexerico. (RIBEIRO, 1997: 179-180)
\end{abstract}

Ribeiro também havia escrito sobre os cudina anos antes, em um texto sobre arte indígena:

\begin{abstract}
Ainda melhor que suas mulheres, diziam os Kadiwéu, eram os antigos kudina, no domínio dos padrões de desenho. Referem-se a homens que assumiam a condição de mulheres, vestindo-se sentando-se comendo e falando como as damas; casando-se com homens da tribo e até concorrendo mensalmente à reclusão das menstruadas, para assim participar das fofocas da aldeia. Alguns padrões específicos de desenhos são atribuídos, ainda hoje, a esses kudina. (RIBEIRO, 1986: 49)
\end{abstract}

Além dos textos de Clastres, Ribeiro, Rodrigues do Prado, Nimuendaju e Métraux, citados até aqui, há ainda outra referência sobre a homossexualidade entre povos indígenas localizados na região compreendida entre o Mato Grosso do Sul e o Paraguai. Refiro-me ao texto de Cancela et. al. (2010) sobre as "vivências e valores referentes aos relacionamentos homossexuais de pessoas das etnias Guarani Nhandeva, Kaiowá e Terena”, na região de Dourados, Mato Grosso do Sul” (: 199). Para Cancela et al, há na literatura sobre o tema uma perspectiva de homossexualidade indígena enquanto algo aprendido a partir dos não-indígenas: a homossexualidade seria, portanto, "uma experiência afetivo-sexual anômala advinda do pós-contato, como uma expressão colonialista da economia de corpos e desejos controláveis pelo dominador" (: 217).

Contudo, o trabalho de Chamorro sobre a corporalidade Guarani nos trará novas informações. Escreve a autora que

La homosexualidad masculina es registrada por Montoya como Ava aky, hombre no
maduro, que em la jerga castellana equivale a "amujerado". Otra denominación es
Ava kuñaeko, "hombre com modos de mujer". Entre los tupinambá, la práctica de la
homosexualidad era aparentemente una conducta normal. Los indios-hembra, según
el estudio de Ronald Raminelli montaban tiendas públicas para servir como
prostitutas. La expresión che atukupe rupi che moangaipa, "pecó conmigo por
detrás", puede ser tanto una referencia a la práctica de sexo anal entre heterosexuales
u homosexuales masculinos. Ya kuimba'e ojoehe ojomenõ y kuimba'e oñomenõ se
refieren al acasalamiento entre varones, traducido por Montoya como "pecado
nefando". Tevi, "ano", es otro término en base al cual se denomina la homosexualidad 
masculina y femenina, como en ava tevíro, "hombre somético", ambotevíro, "lo hago un somético", che mbotevi, me torna somético, y kuña tevíro, mujer somética. Curiosamente, Gabriel Soares, entre otros, registró que el término tibira era aplicado a líderes espirituales que siendo hombres "servían de mujer" en los actos sexuales. (CHAMORRO, 2009: 237-238)

\title{
Ainda sobre os Guarani, Cancela et al (2010: 214) apontam que entre os
}

\section{Guaranis Mbyás o termo para homens homossexuais é guaxu7. O mesmo trecho aparece na entrevista com a líder e professora Jerá Giselda Guarani,}

\begin{abstract}
Ele é guaxu, como nós chamamos a homossexualidade. Em nenhum momento ele quis esconder isso. E foi acolhido mesmo entre os homens. Ele gosta muito de um mito Guarani: guando Nhanderu criou o mundo, fez os homens primeiro. E aí um dia disso para os filhos: "vai lá na terra ver como o povo está." E aí o filho de Nhanderu veio e viu que os homens estavam namorando. E tinha um homem grávido. Aí ele volta para o pai e relata o que está acontecendo. E aí o pai diz: "volta lá e cria um parceiro para esses homens, uma mulher lá na terra.” E aí ele veio e gerou a mulher. E o homem grávido falou assim: "e eu? E agora?" "Não. Você não vai ter o seu filho aqui Nhanderu fez uma morada sagrada para você ficar lá.” E aí ele aceitou. E até hoje ele está lá, em uma morada sagrada. E aí eu digo brincando para o gringo: "está vendo! Gay também existe no mundo dos Guaranis desde que o mundo é mundo! Tem um até grávido!” (TRAULITO, 2010: 6)
\end{abstract}

\section{Ainda quanto aos Mbyá, escreve Ladeira:}

\begin{abstract}
Não teríamos condição, nem é nosso objetivo neste trabalho, discorrer sobre a questão do homossexualismo. Talvez caiba aqui apontar que o homossexualismo entre os Mbya se traduz tão somente na preferência sexual de parceiros do mesmo sexo. É prática comum, principalmente na infância e adolescência, e não discriminada. Aqueles que depois de adultos preferem manter relações com parceiros do mesmo sexo, e que não querem se casar, não precisam necessariamente cumprir as funções do sexo oposto. Como não faz sentido o casamento homossexual, eles permanecem, quase sempre, na casa da mãe. Somente tive conhecimento de um caso de homossexualismo masculino em adulto. (LADEIRA, 2007: 132)
\end{abstract}

\section{Há ainda referências ao tema em Calheiros (2014), a respeito de outro}

\section{grupo Tupi: os Aikewara (povo Tupi-Guarani que vive no estado do Pará).}

E assim diriam os Aikewara - sobretudo as mulheres, repito -, pois sabem da trajetória de um homem que viveu "em outro tempo, em outro lugar", um outro "fulano", conhecido pelo epiteto de ga'ipymonó'monó-tara ("aquele-que-dádemasiadamente-o-ânus"). Tratava-se de um que se transformou em uma, de um que apesar de ter nascido homem crescera como uma mulher (madurou como tal); era uma kusó'angaw (lit. "mulher-simulacro"), era "como os travestis de Marabá", comparava Muretama. Conta-se que esta kusó'angaw recusava as mulheres e mantinha relações sexuais secretas com outros homens. Homens que chamava de irmãos (-ru) - primos paralelos, provavelmente - e que a procuravam por ser uma exímia pintora, coisa que segundo meus amigos, "fazia melhor que as mulheres" - há, aqui, uma alusão aos seus dotes sexuais, naturalmente. Sucedeu-se que esta mulhersimulacro, de tanto fazer sexo com outros - "seu ânus era verdadeiramente insaciável”, diz o mito -, acabou engravidando de um de seus amantes. Uma gestação anormal, contam, pois a despeito de se parecer tanto com uma mulher - semelhança que aumentava conforme tomava outros como amantes -, ga'ipymonó'monó-tara era imperfeita, seu útero não era como a das outras, era "imprestável” (eká-ikatue'yme)

7 Segundo Canese (2000) guaxu quer dizer "veado", o que nos permite entender o termo - e não necessariamente a prática - como algo surgido a partir do convívio com o não-índio. Entre os Xavante testemunhei algo parecido: os mais jovens usam o termo ponere ("veado do campo") para referirem-se jocosamente aos homossexuais não-indígenas ou de outras etnias, sendo que os mais velhos recusam tal conotação. No Brasil "veado" é um termo tabuizado para referir-se aos homossexuais do sexo masculino, de modo que seu uso - mesmo que na língua nativa - nas aldeias parece ir ao encontro do proposto aqui: a estigmatização da homossexualidade entre povos indígenas no Brasil se dá no âmbito do processo de colonização das sexualidades indígenas. 
era verdadeiramente incapaz de "entregar uma pele verdadeira" ao influxo de seu amante. [...] Contudo, esta criança nunca chegou a "cair", ela e sua mãe foram mortas por um que poderia ser o seu pai. O assassino temia que a criança fosse sua (todos os amantes de ga'ipymonó'monó-tara temiam, e não eram poucos), mas não por vergonha ou coisa do tipo, seu medo não era que os outros descobrissem que ele mantinha relações com a kusó'angaw - até mesmo porque, ao que tudo indica, todos da aldeia sabiam quem eram os amantes da kusó'angaw e não havia qualquer conflito em relação a isto [...]. (CALHEIROS, 2014: 251-252)

Outra menção, que o próprio autor (loc. cit.) aponta como semelhante, é aquela descrita por Lagrou, sobre Napu aimbu entre os índios Kaxinawá do

Acre:

\begin{abstract}
"[a autora conta o mito de origem do desenho, conforme contado em kaxinawá por Teresa, durante seu primeiro período de campo] Muka só tinha um filho, Napu ainbu. E quando sentia que ia morrer, ela só tinha a ele para ensinar o que sabia. Ensinou para ele como desenhar, tecer e cantar; e quando morreu e o filho ficou sozinho, ele foi viajar para procurar seus parentes de outra aldeia. Quando chegou à aldeia, seus parentes, que não o conheciam, pensavam que Napu era mulher, porque Napu estava pintado como mulher, vestido como mulher e agia como mulher: 'Vem cá cunhada', falou para suas primas, 'vamos desenhar'. 'Você sabe?', perguntavam, 'sei', disse. E Napu ensinava às mulheres o que tinha aprendido com a mãe. Todos os huni kuin [i.e., kaxinawás] ficaram entusiasmados com e muitos queriam casar com ele. Certo dia uma das suas primas foi tomar banho com Napu e voltou surpreendida. Ela avisou os homens falando: 'não é mulher, é homem, eu vi'. Mas um dos homens estava tão apaixonado por Napu que não quis escutar. Napu falou, "não faz isso comigo', mas o homem insistia e finalmente convenceu Napu de ir com ele para a mata, onde namorou (puikini, no ânus, txutaniki, fazer sexo) e assim engravidou Napu. A criança cresceu e quando era para nascer, sua cabeça não conseguiu sair. Napu morreu e os huni kuin ficaram com raiva do homem que matou Napu que sabia tão bem desenho". [...] A transgressão no mito, que provocou a morte do herói, está na transmissão de um conhecimento fundamentalmente feminino [o desenho] a um homem, o único filho da velha que aprendeu o desenho. Napu, quase mulher, foi incapaz de parir o filho. O termo Napu ainbu é usado pelos Kaxinawa para se referir a "homens que gostam de namorar outros homens". (LAGROU, 2007: 194-195)
\end{abstract}

É interessante mencionar desde já que o relato de Lagrou, acima, vai ao encontro de um depoimento ouvido por mim por um jovem Kaxinawá em agosto de 2014:

Bom, no tempo que vivi na minha aldeia existiam alguns homossexuais assumidos! Travestis, desconheço! Em relação ao preconceito, não me recordo de ter presenciado ou ter ouvido sobre. Na adolescência, não sei se é uma regra, mas me relacionei com alguns garotos, mas eles não necessariamente sejam homossexuais hoje! Na minha língua, quando se refere a um homossexual, fala-se "huni aimbu". Huni, significa homem. Então, numa tradução direta ficaria "homem -mulher " [ou,] "o homem que é mulher".8

Outras análises recentes também apontam para práticas homossexuais entre os Karajá (Macro-Jê), grupo da mesma família linguística dos Xambioá (mencionados aqui a partir de Couto de Magalhães, 1876). Entre os Karajá, Torres (2011) aponta, partindo do relato de uma enfermeira, que "entre os Karajá tem muitos bissexuais, é muito comum encontrar homem casado que mantém relações sexuais com vários outros homens, os que se assumem como 
homossexuais nas aldeias são muitos, eles sempre têm 5, 6 casos com homens casados nas aldeias” (: 189). Entre os Javaé (também da família Karajá), a tese de Patrícia de Mendonça Rodrigues (2008) aponta a existência de pajés homossexuais que cobram serviços sexuais dos homens desejados, em troca das atividades xamânicas (:762), sendo que os Javaé possuem um termo para homossexual (hawakyni) que significa "falsa mulher" (:414-415). Para permanecer entre os Jê, temos o relato de Crocker, a partir de Panet:

\begin{abstract}
Crocker menciona a história de dois homossexuais que teriam existido nos anos 1930. Como lhe disseram, eles se vestiam, como mulheres, com panos de enrolar um pouco acima dos joelhos, apenas diferenciando-se do costume feminino em usá-los um pouco abaixo dos joelhos. Um dos homossexuais era usado como parceiro passivo nas relações sexuais, mas por pouco tempo. Ambos trabalhavam na roça de suas parentas, mas nenhum deles corria com tora, nem frequentavam as reuniões masculinas do pátio. Segundo Crocker, a homossexualidade era expressa pela tomada de certos papéis e atividades femininas e pela rejeição dos papeis e atividades masculinas. (PANET, 2010: 224)
\end{abstract}

Como se vê, não são poucas as descrições sobre as práticas homossexuais entre os povos indígenas brasileiros. Entendo que haja, ainda, várias outras fontes às quais, dadas minhas próprias limitações de tempo e recursos, infelizmente, não pude incorporar a este esforço de sistematização em torno do tema9. A seguir buscaremos apontar, de modo bastante breve, algumas das referências e contribuições recentes que tratam mais diretamente sobre a temática.

\title{
A temática pelo olhar da Antropologia: contribuições recentes
}

Ao contrário do que se pode supor, há já um conjunto de reflexões mais ou menos consolidadas na etnologia brasileira sobre a temática. De certa forma, pode-se dizer aqui, à guisa de hipótese, que no Brasil venham surgindo reflexões sobre sexualidade indígena enquanto campo gradualmente autônomo, se descolando de temas já tradicionais na antropologia brasileira, como os estudos de gênero, sobre pessoa e sobre corporalidade indígenas.

Exemplo disso foi a publicação recente de um dossiê da revista Cadernos Pagu (Unicamp) dedicado ao tema “Alteridade, Gênero, Sexualidade, Afeto"10 e de uma coletânea, organizada por Ivo Brito (2011) intitulada Sexualidade e 
Saúde Indígenas. Dessas publicações destacamos os textos de Rosa (2013) e Mott (2011).

Em seu artigo, Rosa (2013) relata um relacionamento homossexual entre duas primas Tikuna, destacando o caráter duplamente "indesejado" da união entre ambas: um casamento entre pessoas do mesmo sexo, bem como entre parentes próximas. Dessa maneira, uma de suas interlocutoras cita na aldeia práticas como "aconselhamentos levados à cabo pelo conselho de anciões das aldeias", a presença de uma "polícia indígena que, entre outras atribuições, fiscaliza os namoros, prende se for necessário”, e de um pastor neopentecostal, cuja função seria "exercer os consertos, por meio dos sermões e da conversão, tornando o sujeito alguém de corpo limpo (: 81 , itálicos no original). É registrado ainda no texto de Rosa, a categoria "amor proibido", sobre o qual explica uma de suas interlocutoras:

\begin{abstract}
Isso é quando a gente não pode estar junto com quem se gosta, porque é feio, atrapalha as relações dos nossos parentes; ou a comunidade não aceita. A (Fulana) tem a garota dela e pode estar na comunidade delas porque a família dela tem poder político, aí tudo fica diferente. (...) tem as igrejas agora que aceitam esses romances, esses amores proibidos, mas não acaba os julgamentos. (...) os jovens tem apanhado dos pais porque são gays; se matam, ficam tristes. (ROSA, 2013: 82)
\end{abstract}

Há aí elementos sobre o controle eclesiástico sobre a sexualidade indígena, bem como da repercussão política no âmbito da própria aldeia, das agressões, preconceitos e suicídios de indígenas homossexuais. Este não é, como veremos um caso isolado, havendo vários relatos sobre tais questões também nas regiões do Xingu, do alto Rio Negro e entre indígenas do Nordeste.

Destacamos ainda o capítulo intitulado "A homossexualidade entre os índios do Novo Mundo antes da chegada do homem branco", escrito por Mott (2011), onde é traçado um percurso histórico11 dos registros sobre homossexualidade indígena no Novo Mundo (incluindo populações do México e Peru). Mott (2011: 89) também irá indicar uma associação entre homossexualidade e xamanismo. Penso que isso convirja com outras informações trazidas por outros autores- como Chamorro e Rodrigues, ambas mencionadas aqui.

Outra coletânea foi recentemente publicada sobre sexualidade indígena na revista Cadernos de campo12, com textos apresentados no evento Foucault na Amazônia? Sexualidades indígenas, ocorrido no Museu Nacional (Rio de 
Janeiro) em junho de 2015, com especial destaque para o texto publicado por Diógenes Cariaga, intitulado Gênero e sexualidades indígenas: alguns aspectos das transformações nas relações a partir dos Kaiowa no Mato Grosso do Sul. Nele, o autor trabalha a homossexualidade de jovens Kaiowá da região de Dourados (Mato Grosso do Sul), desde uma perspectiva geracional e em um diálogo bastante promissor com a literatura Guarani e com teóricos mais “clássicos” da etnologia indígena (Cariaga, 2015).

Mas é no nordeste do Brasil que vêm surgindo de forma mais intensa diversos trabalhos sobre homossexualidade indígena. Destaco aqui o texto de Silva (2012) intitulado "Há lugar para a homossexualidade num regime de índio?”, a partir de trabalho realizado junto aos Pataxó. O autor aponta o termo Mañay como a expressão na língua daqueles indígenas para designar "homossexual", indicando ainda as formas a partir das quais o grupo negava aos não-indígenas a existência de pessoas homossexuais em sua comunidade. $\mathrm{O}$ autor aponta como a homossexualidade entre aqueles índios é sistematicamente negada em um contexto interétnico, causando aos indígenas desconforto os eventuais questionamentos, por parte de não-índios, sobre a existência, ou não, de "índios gays".

Por outro lado, temos na Paraíba a maior parte da produção recente sobre homossexualidade entre índios do Nordeste. Refiro-me aqui aos trabalhos de Guerra (2013), Nascimento (2014) e Tota (2012, 2013a, 2013b; 2015).

Verônica Alcântara Guerra, apresentou trabalho na VI Reunião Equatorial de Antropologia/XIII Reunião dos Antropólogos do Norte e Nordeste (Fortaleza, 2013) intitulado “Despeitadas': Travestis da aldeia indígena para o mundo", cujo resumo informa:

\begin{abstract}
Esta comunicação pretende percorrer os caminhos e histórias de vida de duas travestis que nasceram em aldeias indígenas na região do Litoral Norte da Paraíba, enfatizando o processo de transformação de seus corpos mediante os trânsitos e deslocamentos realizados por elas. De um lado Karla, a primeira travesti da aldeia, garoto que se sentia atraído por homens e mulheres, saiu da aldeia para a cidade de Mamanguape onde descobriu o hormônio e o trabalho na prostituição, levando-a a trilhar vários caminhos entre cidades e capitais do Nordeste. Do outro lado, encontrase Kelly, travesti que logo cedo conheceu as delícias e dores que morar e trabalhar como prostituta na Itália, onde fez aplicação de silicone nos braços para disfarçar os músculos e ficar mais feminina. Nesse aspecto o corpo parece ter uma dupla função, primeiro: encaixar ao personagem que elas desejam encenar na sociedade em que vivem, segundo: o corpo construído para consumo no mercado do sexo. (GUERRA: 2013)13
\end{abstract}

13 Disponível em http://www.reaabanne2013.com.br/site/wp-content/uploads/2013/o7/GrupoTrabalho11.pdf, acessado em 28 de maio de 2015 . 
Em que pese, infelizmente, Guerra não haver publicado seu trabalho nos Anais do evento, algumas de suas questões são examinadas em texto escrito por sua orientadora de pesquisa, Silvana de Souza Nascimento.

Nele, a autora aponta haver identificado em sua pesquisa

\begin{abstract}
pelo menos oito a dez travestis que moram em áreas indígenas na região entre Rio Tinto e Baía da Traição. Segundo elas, "se você quiser ver bicha lá, é só o que tem". Algumas estão na Itália, outras retornaram da Europa, outras ainda almejam se mudar para lá. Da Itália para a aldeia, há um circuito que mobiliza travestis jovens no Brasil, e travestis "das antigas" e "coroas", na Europa, permitindo a circulação dessas pessoas em contextos distintos, circulação esta que se dá por relações de amizade e de compadrio (ou seja, "madrinhas" que incentivam e patrocinam as viagens). (NASCIMENTO, 2014: 382)
\end{abstract}

Assim, ao longo de seu texto acompanhamos a história de algumas dessas travestis indígenas (Potiguara), como o caso de Cláudia, a qual mesmo não tendo sido aceita em princípio por seus pais, atualmente "pode circular entre a aldeia, onde alimenta seus laços familiares, e outros espaços urbanos em que se diverte, trabalha e cria relações afetivo-sexuais" (idem: 383). A autora também registra a existência do concurso "Beleza Gay Indígena” (: 386), bem como a organização da

Parada LGBT da Baía da Traição teve a sua segunda edição em 2011 e foi organizada por um rapaz homossexual, militante, filho de uma liderança política reconhecida na área indígena potiguara. Este rapaz tem um projeto de implantar uma associação LGBT indígena que possa mobilizar jovens de suas aldeias. (: 406)

Também sobre os Potiguara escreve Martinho Tota (Tota, 2013a e 2015), a partir de pesquisa realizada como membros da Organização dos Jovens Indígenas Potiguara (OJIP). No conjunto de seus trabalhos fica clara a necessidade de se compreender as relações dos jovens homossexuais indígenas Potiguara com sua sexualidade a partir dos movimentos de afirmação de identidade étnica em grupos indígenas do nordeste do país - o mesmo podendo se afirmar, em alguma medida, dos trabalhos de Nascimento, Guerra e Silva.

Martinho Tota (2012, 2013b e 105) parece indicar neste sentido, analisando como etnicidade e sexualidade se interseccionam - apontando, inclusive, para as especificidades dos índios do Nordeste14 (2013b: 323). Dessa maneira, sua pesquisa aponta que atualmente,

\footnotetext{
Ao menos no caso dos índios vivendo no Nordeste brasileiro, o que se deu foi uma completa disjunção entre o discurso étnico e questões referentes a gênero e, principalmente, sexualidade. Houve - o que não deixa de ser compreensível em termos políticos - uma produção abundante enfocando o primeiro termo desta equação e um total apagamento de outras instâncias da vida social desses coletivos.
} 
Com isso, vemos em diversas monografias o que [Alcida] Ramos chama de "índio hiper-real"15, aquele que "desempenha o papel que os brancos lhe atribuíram", sendo "artificialmente" instituído como "um 'outro' (...) aceitável, enquanto se ignora a alteridade das pessoas que existem em carne e osso". (: 339)

Assim, Tota adota uma postura crítica - com a qual particularmente concordo - tanto a setores da academia quanto a algumas lideranças indígenas: a uns interessa o retrato do índio "hiper-real” (Ramos, 1995), destituído de sexualidade; aos outros, impõe-se o silenciamento16 diante da inconveniência em "ter os etnônimos que representam associados a indivíduos cujos comportamentos escapam à heteronormatividade" (loc. cit.).

Outro texto, também de autores localizados na Paraíba (Laionel Vieira da Silva e

Bruno Rafael Silva Nogueira Barbosa, ambos da UFPB) foi recentemente publicado na revista Mandrágora, da Universidade Metodista de São Paulo. Neste artigo - intitulado Entre cristianismo, laicidade e estado: As construções do conceito de homossexualidade no Brasil - os autores traçam um histórico dos termos utilizados historicamente para referirem-se às práticas homossexuais indígenas, fazendo uso, sobretudo, das referências jesuíticas.

Como se vê, um conjunto de escritos mais recentes já apresenta reflexões mais estruturadas em torno da homossexualidade indígena, seja em um contexto comparado (como os textos de Mott, Trevisan e Cancela), ou desde de um olhar a partir das relações interétnicas (como Silva, Nascimento, Guerra e Tota). Somo a esses textos meus próprios (Fernandes, 2014a,2014b, 2014c e 2015a e 2015b), a partir de um esforço de se compreender os processos aqui descritos à luz do movimento two-spirit norte-americano e da literatura decolonial.

Uma listagem sobre a produção recente não estaria completa sem relacionar, aqui, o texto publicado por Gontijo e Erick (2015), no qual os autores tratam "da diversidade sexual e de gênero em contextos rurais ou interioranos e em situações etnicamente diferenciadas nas regiões Norte, Nordeste e, em geral, na Amazônia” (: 29). O texto é bastante interessante, por ampliar o espectro de análise para uma esfera regional, fazendo farto (e excelente) uso de teóricos 
queer e da literatura brasileira sobre o tema. Nesse mesmo ano, o texto de Maranhão Filho (2015) virá a chamar a atenção para rituais de cura de travestis e homossexuais indígenas em igrejas neopentecostais na região do alto rio Negro. Esses dois textos, ao lado daqueles produzidos por Tota e Fernandes, chamam a atenção para o caráter heteronormado não apenas da academia, mas de vários setores de movimentos sociais, indígenas e campesinos, como se a homossexualidade correspondesse a uma contaminação de um sujeito essencial, "hiper-real”, puro - e portanto, a-histórico.

Esta crítica ganha ainda mais força em um texto produzido recentemente por Manuela Lavinas Picq (professora na Universidade San Francisco de Quito, Equador) e Josi Tikuna (aluna de Antropologia no Instituto de Natureza e Cultura, da Universidade Federal do Amazonas), intitulado Sexual Modernity in Amazonia ("Modernidade sexual na Amazônia")17. Neste texto as autoras apontam, por exemplo, como as regras Tikuna respeitam casais do mesmo sexo, sendo o casamento algo necessariamente entre pessoas de diferentes clãs, não importando se são, ou não, de sexos diferentes. Desta maneira, os autores que buscaram compreender as regras de casamento naquele povo erraram por não haver percebido as uniões homoafetivas como permitidas. Mais que isso, o texto indica que, para as mulheres Tikuna, "a diversidade sexual é intrinsecamente indígena, enquanto a discriminação sexual foi trazida pelas igrejas evangélicas”, incutindo aí a ideia de que tais uniões seriam pecaminosas. Desta forma, as Ngüe Tügümaêgüé (mulher que faz sexo com outra mulher) e os Kaigüwecü (homem que faz sexo com outro homem) seriam associados à poluição e abominação. Ao final, concluem as autoras - utilizando-se de autores two-spirit:

\footnotetext{
Tonar a Amazônia queer é um projeto teórico. Queer no sentido de mover-se além de categorizações e fronteiras políticas. Queer no sentido de tornar visível como o colonialismo e sexualidade interagem dentro da lógica perversa da modernidade. Pesquisadores expuseram a heteronormatividade do colonialismo, insistiram no valor de descolonizar estudos queer e queerificar os estudos descoloniais. As sexualidade amazônicas lançam luz na complementariedade das perspectivas queer e indígena para pensar a modernidade global18. (PICQ e TIKUNA, 2015, versão eletrônica)
}

17 Texto publicado em 2 de julho de 2015 e acessível pelo link http://www.e-ir.info/2015/o7/o2/sexual-modernity-inamazonia/, acessado em julho de 2015. Uma versão em português do texto, intitulada "Modernidade sexual na Amazônia", está disponível no link https://geofaust.wordpress.com/2015/07/14/modernidade-sexual-na-amazonia/, acessado também em julho de 2015.

18 "To queer Amazonia is a theoretical project. Queer in the sense of moving beyond categorizations and political borders. Queer in the sense of making visible how colonialism and sexuality interact within the perverse logics of modernity. Scholars exposed the heteronormativity of colonialism (Smith 2010), insisted on the value to decolonize queer studies and queer decolonial studies (Driskill et al. 2011; Rifkin 2011). Amazon sexualities shed light on the complementarity of queer and Indigenous perspectives for thinking global modernity." 
Textos como estes, escritos em colaboração com indígenas no Brasil, assim como a organização de jovens indígenas LGBTIQ no nordeste, referidos na última parte deste artigo, talvez apontem para a possibilidade de uma crítica dos processos históricos de normalização e heterossexualidade compulsória situados aqui.

Em uma nota pessoal - e peço licença aos pareceristas e leitores confesso que, em minha opinião, não parece ser mero acaso que as críticas mais contundentes a esses processos sejam, justamente, aquelas baseadas geográfica ou epistemologicamente nas periferias. No esforço que temos pela frente, de se indigenizar o queer (ou de se queerificar o indígena?), talvez seja necessário consolidar ainda mais a sexualidade como campo autônomo e crítico, inclusive de estruturas e cânones da própria academia. Mas isso é tema para outro artigo.

\section{Referências Bibliográficas}

ABREU, Capistrano de. Rã-txa hu-ni-ku-i. Grammatica, textos e vocabulário

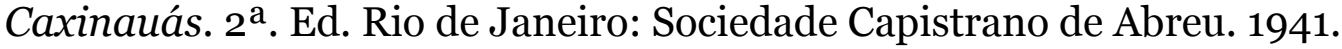

ALEXANDRINO, Ronaldo. A suposta homossexualidade. Dissertação de Mestrado em Educação. Campinas: Unicamp. 2009.

BALDUS, Herbert. Ensaios de etnologia Brasileira. São Paulo, Rio de Janeiro, Recife: Companhia Editora Nacional. 1937.

BRITO, Ivo. (Org.). Sexualidade e saúde indígenas. Brasília, Paralelo 15. 2011.

CALHEIROS, Orlando. Aikewara. Esboços de uma sociocosmologia tupiguarani. Tese de Doutorado em Antropologia Social, PPGAS-UFRJ. Rio de Janeiro, 2014.

CANCELA, Cristina Donza; SILVEIRA, Flávio Leonel Abreu da; MACHADO, Almires. "Caminhos para una pesquisa acerca da sexualidade em aldeias indígenas no Mato Grosso do Sul”, Rev. Antrop. 53(1): 199-235. 2010.

CANESE, Natalia K. de; ALCARAZ , Feliciano A. Diccionario Guarani/Español - Español/Guarani. Assunção: Instituto Superior de Línguas, Asunción, Universidad Nacional de Asunción. 2000. 
CARIAGA, Diógenes. "Gênero e sexualidades indígenas: alguns aspectos das transformações nas relações a partir dos Kaiowá no Mato Grosso do Sul”. Cadernos de campo, São Paulo, n. 24, p. 441-464, 2015.

CARNEIRO, Robert. "Extra-Marital sex freedom among the Kuikuru Indians of Mato Grosso”. Revista do Museu Paulista N.S., X. 1956/58. São Paulo. 1958.

CARVAJAL, Gaspar de. Descobrimentos do rio das Amazonas, traduzidos e anotados por C. de Melo-Leitão. São Paulo: Companhia editora nacional. 1941.

CHAMORRO, Graciela. Decir el Cuerpo: Historia y etnografia del cuerpo em lós pueblos Guarani. Asunción, Tiempo de Historia, Fondec. 2009.

COLINI, Giuseppe Angelo. "Studio storico ed etnográfico del dott. G. A. Colini". Em: BOGGIANI, Guido. I Caduvei (Mbayá o Guaycuru), Viaggi d’um artista nell'America Meridionale. Roma: Ermanno Loescher \& C. ${ }^{\circ} 1895$.

D'EVREUX, Yves. Viagem ao Norte do Brasil feita nos annos de 1613 a 1614 pelo padre Ivo D'evreux, religioso capuchinho, publicada conforme o exemplar unico conservado na Biblioteca Imperial de Pariz. Maranhão: Typ. Do Frias, 1874 .

. Voyage au nord du Brésil (1615). Édition critique établie par Franz OBERMEIER. Kiel: Westenseeverlag-Verlag, 2012.

DESCONHECIDO. Cartas Avulsas: 1550-1568. Série Publicações da Academia Brasileira, Cartas Jesuíticas II. Rio de Janeiro: Officina Industrial Gráfica. 1931.

FERNANDES, Estevão R. "Homossexualidades indígenas y descolonialidad: algunas reflexiones a partir de las críticas two-spirit”. Tabula Rasa: Revista de Humanidades (Bogota). v. 20, p. 135-157, 2014 a.

- "Homossexualidade Indígena no Brasil: Desafios de uma pesquisa”. Novos Debates - Fórum de Debates em Antropologia. v. 1, p. 26-33, $2014 b$.

- "Pensando de forma não situada: dilemas no estudo das homossexualidades indígenas no Brasil”. Élisée - Revista de Geografia da UEG. v. 3, p. 157-167, 2014c.

"Ativismo Homossexual Indígena: Uma Análise Comparativa entre Brasil e América do Norte”. Dados (Rio de Janeiro), v. 58, p. 257-294, 2015a.

- "Decolonizando sexualidades: Enquadramentos coloniais e homossexualidade indígena no Brasil e nos Estados Unidos". Tese de Doutorado em Ciências Sociais (Estudos comparados sobre as Américas) apresentada no Centro de Pesquisa e Pós Graduação da Universidade de Brasília. Brasília: Ceppac/UnB. 2015b.

FOUCAULT, Michel. História da Sexualidade I: A vontade de saber. Rio de Janeiro: Graal. 1988. 
FREYRE, Gilberto. Sobrados e Mucambos. Coleção Intérpretes do Brasil, vol. 2. Rio de Janeiro: editora Nova Aguilar, 2002.

GANDAVO, Pero de Magalhães de. Historia da Provincia de Santa Cruz a que vulgarmente chamamos Brasil. Lisboa: Typographia da Academia Real das Sciencias. 1858.

GOMES, Aguinaldo Rodrigues; NOVAIS, Sandra Nara da Silva. "Práticas sexuais e homossexualidade entre os indígenas brasileiros". Caderno Espaço Feminino (Online), v. 26, p. 44-57, 2013.

GONTIJO, Fabiano, ERICK, Igor. "A Diversidade Sexual e de Gênero em Contextos Rurais e Interioranos no Brasil: ausências, lacunas, silenciamentos e... exortações”. Aceno, Vol. 2, n. 4, p. 24-40. Ago-Dez., 2015

GREGOR, Thomas. Mehinaku. Chicago: Chicago University Press. 1977.

Anxious pleasures: the sexual lives of an Amazonian people. Chicago: University of Chicago Press 1985.

GUERRA, Verônica Alcântara. "Despeitadas': Travestis, da aldeia indígena para o mundo". Trabalho apresentado no Grupo de Trabalho Culturas corporais, sexualidades e reconhecimentos: novas moralidades em debates. IV Reunião Equatorial de Antropologia/XVIII Reunião de Antropólogos do Norte e Nordeste. Fortaleza, 2013.

HERCKMAN, Elias. "Descripção geral da Capitania da Parahyba". Revista do Instituto Archeologico e Geographico Pernambucano, tomo V, n. 31, p. 239288. Recife: Typographia Industrial. 1886.

HUGH-JONES, Christine. From the milk river: spatial and temporal processes in Northwest Amazonia. Nova Iorque: Cambridge University Press. 1979.

LADEIRA, Maria Inês. O caminhar sob a luz: território mbya à beira do oceano. São Paulo: Editora Unesp, 2007.

LAGROU, Els. A fluidez da forma: arte, alteridade e agência em uma sociedade amazônica [Kaxinawá, Acre]. Rio de Janeiro: Top Books, 2007.

LEA, Vanessa R..O som do silêncio (Paul Simon). Cad. Pagu. n.41, pp. 87-93. 2013 .

LÉRY, Jean de. Viagem à terra do Brasil. São Paulo. Livraria Martins. 1941.

. Voyage au Brésil. Lausanne: Bibliothèque romande, 1972.

History of a voyage to the land of Brazil, otherwise called America. Berkeley: University of California Press. 1990.

LÉVI-STRAUSS, Claude. "The social use of kinship terms among Brazilian Indians". American Anthropologist, New Series, Vol. 45, N. 3, Part 1 (Jul. - Sep., 1943). Pp. 398-409. 1943. 
Tristes Trópicos. São Paulo: Companhia das Letras. 1996. O cru e o cozido (Mitológicas I). São Paulo: Cosac \& Naify.

2004 .

MAGALHÃES, Couto de. "Parte II: Origens, costumes e região selvagem". $O$ Selvagem. Rio de Janeiro: Typographia da Reforma. 1876.

MARANHÃO FILHO, Eduardo Meinberg de Albuquerque. "A Pomba-gira Lady Gaga e a travesti indígena: (Re/des) fazendo gênero no Alto Rio Negro, Amazonas". Mouseion, Canoas, n.22, p. 151-175. Dez. 2015.

MÉTRAUX, Alfred. "Ethnography of the Chaco". Em: STEWARD, J. H. (Ed). Handbook of South American Indians. Vol 1. The Marginal Tribes. Smithsonian Institution Bureau of American Ethnology. Bulletin 143. Washington: United States Government Printing Office. 1948.

MOTT, Luiz. "A homossexualidade entre os índios do Novo Mundo antes da chegada do homem branco". BRITO, Ivo et al. Sexualidade e saúde indígenas. Pp. 83-94. Brasília: Paralelo 15. 2011.

MURPHY, Robert; QUAIN, Buell Quain. The Trumaí Indians of Central Brazil. Seattle \& London: University of Washington Press. 1955.

NASCIMENTO, Silvana de Souza. "Variações do feminino: circuitos do universo trans na Paraíba”. Revista de Antropologia, v. 57, pp. 376-411, 2014.

NÓBREGA, Manuel da. Cartas do Brasil (1549-156o). Rio de Janeiro: Officina Industrial Graphica. 1931.

NIMUENDAJU, Curt. "The Tukuna”. Em: LOWIE, R. (org.), Publications in American Archaeology and Ethnology. Berkeley/Los Angeles, University of California Press, vol. 45. 1952.

As lendas da criação e destruição do mundo como fundamento da religião dos Apapocúva-Guarani, São Paulo: Hucitec/Edusp. 1987.

OLIVEIRA, João Oliveira. "A problemática dos 'índios misturados' e os limites dos estudos americanistas: um encontro entre antropologia e história". In: Ensaios em antropologia histórica. pp. 99-123. Rio de Janeiro: Editora UFRJ. 1999.

PANET, Rose-France de Farias. 'I-mã a Kupên prãm': Prazer e sexualidade entre os Canelas. Tese de Doutorado em Políticas Públicas e em Antropologia, Universidade Federal do Maranhão; École Pratique de Hautes Études. 2010.

PICQ, Manuela Lavinas; TIKUNA, Josi. "Sexual modernity in Amazônia". Einternational relations. Disponível em http://www.eir.info/2015/07/02/sexual-modernity-in-amazonia/, acessado em agosto de 2015. Artigo publicado em 2 de julho de 2015. 
RAMOS, Alcida Rita. "O índio hiper-real”. Revista Brasileira de Ciências Sociais. 28(10): pp. 5-14. 1995.

RIBEIRO, Darcy. Os índios e a civilização. Petrópolis: Vozes. 1979.

"Arte Índia". Em: RIBEIRO, Darcy (Ed.) Suma etnológica brasileira, volume 3: Arte índia. Petrópolis: Vozes. 1986.

. Confissões. São Paulo: Companhia das Letras. 1997.

RODRIGUES, Patrícia de Mendonça. A caminhada de Tanyxiwè: Uma teoria Javaé da História. Tese de Doutorado em Antropologia (versão em português). Chicago: University of Chicago, 2008.

ROSA, Patricia Carvalho. "Romance de primas com primas e o problema dos afetos: parentesco e micropolítica de relacionamentos entre interlocutores Tikuna, sudoeste amazônico”. Cad. Pagu. n. 41, pp. 77-85, 2013 .

ROSÁRIO, José Manuel. "História dos índios cavalleiros, ou da nação guaycurú, escripta no real presídio de Coimbra por Francisco Rodrigues do Prado Trasladada de um manuscripto offerecido ao Instituto pelo Socio Correspondente José Manuel do Rosário". Revista do Instituto Histórico e Geographico do Brazil, Tomo I, n. 1, 1ㅜ. Trimestre de 1839.

SILVA, Laionel Vieira da; BARBOSA, Bruno Rafael Silva Nogueira. "Entre cristianismo, laicidade e estado: As construções do conceito de homossexualidade no Brasil”. Mandrágora (Universidade Metodista de São Paulo). v.21. n. 2, p. 67-88, 2015.

SILVA, Paulo de Tássio Borges da. "Há lugar para a homossexualidade num regime de índio?”. Em: Anais do VI Congresso Internacional de Estudos sobre a Diversidade Sexual e de Gênero da Associação Brasileira de Estudos da Homocultura-ABEH. Salvador, 2012.

SOUSA, Gabriel Soares de. Tratado descritivo do Brasil em 1587; edição castigada pelo estudo e exame de muitos códices manuscritos existentes no Brasil, em Portugal, Espanha e França, acrescentada de alguns comentários por Francisco Adolfo de Varnhagen. Belo Horizonte, Editora Itatiaia. 2000.

STADEN, Hans. Primeiros registros escritos e ilustrados sobre o Brasil e seus habitantes. São Paulo: Editora Terceiro Nome. 1999.

STEINEN, Karl von den. "Entre os Borôros (Tradução do cap. XVII do livro Unter den Naturvölkern Zentral-Brasiliens, por Basílio de Magalhães)”. Revista do Instituto Historico e Geographico Brasileiro, Tomo LXXVIII, Parte II, p. 391-490. 1915 .

TORRÃO FILHO, Amílcar. Tríbades galantes, fachonos militantes: homossexuais que fizeram história. S. Paulo: Summus, 2000.

TORRES, Maristela Souza. Mulher karajá. Desvendando tradições e tecendo inovações: diálogo sobre as demandas de gênero. Tese de doutorado. PUC/SP. 2011. 
TOTA, Martinho. Entre as diferenças: gênero, geração e sexualidades em contexto interétnico. Tese de Doutorado em Antropologia Social. Rio de Janeiro: PPGAS/UFRJ. 2012.

"Eixos, nexos e câmbios da diferença: discursos e trajetórias políticas envolvendo etnicidade, homossexualidade e religião". Bagoas: Revista de Estudos Gays, v. 7, pp. 295-322, 2013 a.

Entre as diferenças: gênero, geração e sexualidades em contexto interétnico. Rio de Janeiro: Multifoco, 2013b.

. "Cinco Vidas: travestilidades, gênero, sexualidades e etnicidades no interior da Paraíba”. Revista de Antropologia (USP), 58(2), 2015

TRAULITO. Entre dois mundos: Entrevista com Jerá Giselda, líder Guarani e Professora. Revista Traulito n.2. Julho de 2010, Disponível em http://companhiadolatao.com.br/traulito/wpcontent/uploads/2011/o1/traulitoo2-jera.pdf, acessado em setembro de 2014. 2010.

TREVISAN, João Silvério. Devassos no paraíso: A homossexualidade no Brasil, da colônia à atualidade. 6. ed. Rio de Janeiro: Record, 2004.

VARNHAGEN, Francisco Adolpho de. Historia geral do Brazil, isto é, do descobrimento, colonisação, legislação e desenvolvimento deste estado, hoje imperio independente, escripta em presença de muitos documentos autenticos recolhidos nos archivos do Brazil, de Portugal, da Hespanha e da Hollanda. Tomo primeiro, Rio de Janeiro: Casa de E. e H. Laemmert, 1854.

VESPÚCIO, Américo. Novo Mundo: As cartas que batizaram a América. São Paulo: Editora Planeta do Brasil, 2003.

WAGLEY, Charles. Welcome of Tears, Oxford University Press. 1977.

WAGLEY, Charles; GALVÃO, Eduardo. The Tenetehara Indians of Brazil. New York: Colombia University Press. 1949. 